\title{
Study of subcell parameters, grain size and dielectric properties of Potassium Sodium Niobate mixed system
}

\author{
K. Singh ${ }^{*}$, M. Uniyal, S.C. Bhatt and B.S. Semwal \\ Dielectric and ultrasonic laboratory, Department of Physics, \\ HNB Garhwal University, Srinagar (Garhwal)- 246174, India
}

\begin{abstract}
Pellets of $\mathrm{K}_{1-\mathrm{x}} \mathrm{Na}_{\mathrm{x}} \mathrm{NbO}_{3}$ mixed system of different concentration have been prepared by solid solution reaction method. The subcell parameters \& grain size have been calculated using $\mathrm{X}$ ray diffraction data for mixed $\mathrm{K}_{1-\mathrm{x}} \mathrm{Na}_{\mathrm{x}} \mathrm{NbO}_{3}$ system where $\mathrm{x}$ is varied from $0,20,40,50$, 80, $100 \%$. The variation of unitcell parameters and grain size with composition, at room temperature have been reported. Dielectric constant and loss tangent at room temperature and at different frequencies have also been reported.
\end{abstract}

\section{INTRODUCTION}

Potassium Sodium Niobate (PSN), ceramics with perovskite structure is a promising piezo- ceramic material due to relatively low dielectric constant and high electromechanical coupling coefficient, especially near the equimolar composition. These properties makes the material desirable for certain solid ultrasonic delay line applications which require the use of thin - section transducers. An investigation of ceramics in the system sodium potassium niobate was prompted by certain solid ultrasonic delay line requirements. At the frequencies employed thin transducer section must be used with high dielectric constant materials. In thin sections any appreciable electroded area results in high capacitance. The associated problems in circuitry are simplified if the capacitance of the transducer can be kept low. At the same time, high electromechanical coupling coefficient are desirable in order to obtain large bandwidths ${ }^{1}$. Several investigators ${ }^{2-5}$ have established with the help of high temperature optical and

\footnotetext{
${ }^{*}$ Corresponding author
} 
$\mathrm{X}$-ray diffraction studies that several phase transitions with high spontaneous polarization occur between $-200^{\circ} \mathrm{C}$ and $600^{\circ} \mathrm{C}$ in this system. These ceramics are difficult to sinter and the studies on the influence of rare- earth doping are meager. Air sintering of these materials required long soaking periods for sufficient densification ${ }^{5}$ (Narayana Murty et. al. 1990). The structure at room temperature was basically of the orthorhombic type with a small perovskite subcell but the perovskite units possessed monoclinic symmetry ${ }^{6}$.

Single- crystal diffraction experiments are difficult with ferroelectric materials of the perovskite type because of the difficulty of getting good untwinned single crystals. On the other hand, it is a simple matter to obtain a diffraction pattern from a powder sample. In this communication we have taken XRD pattern and report the effect on the lattice parameter and grain size of different concentration of starting materials.

\section{PREPARATION OF MATERIALS}

The raw materials used for preparing the composition for this system were sodium carbonate, potassium carbonate and niobium pentaoxide. The starting materials were dried at $200^{\circ} \mathrm{C}$ for one hour to remove absorbed moisture. The $\mathrm{K}_{2} \mathrm{CO}_{3}$ had to be handled very carefully in order to prevent it from absorbing measurable quantities of moisture during the material formation procedure. Six compositions were prepared by weighing the sodium carbonate, potassium carbonate and niobium pentaoxide (starting materials) in proper proportion varying from $\mathrm{NaNbO}_{3}$ to $\mathrm{KNbO}_{3}$ by a step of $20 \%$ and one of equal (50-50) composition. Each composition was manually dry mixed for 30 minute and wet mixed using reagent methyl alcohol and mullet mortar and pestle for 30 minute. The mixture is calcined in a platinum crucible in air at $950^{\circ} \mathrm{C}$ for one hour for carbonate removal. After cooling in dry air the calcines were weighed to ensure complete carbonate removal.

The pre-sintered mixture was ground and pressed into disks of $8 \mathrm{~mm}$ diameter. The disks were placed on a platinum crucible and sintered in air at $1050^{\circ} \mathrm{C}$ for 25 hour except $\mathrm{NaNbO}_{3}$, which is sintered at $1200^{\circ} \mathrm{C}$ due to its high melting point.

\section{CHARACTERIZATION}

Out of various possible X-ray diffraction methods, the powder method is of special importance. Also it is the most convenient method by which diffraction data can be obtained from the crystalline materials. These data, which depend on the unitcell parameters are unique for a particular substance and thus can be employed for its identification. The powder method is the quickest possible means of achieving this. 
Room temperature X-ray diffraction patterns of all the prepared compositions have been obtained on a SEIFERT 3000P, X-ray diffractometer using filtered CuK $\alpha 1$ radiation of $1.540598 \AA$ wavelength, in which $\mathrm{Ni}$ is used as filter. The instrument is well calibrated with the Silicon standard sample and the lines obtained are matching with the standard lines. The perovskite subcell parameters were obtained by using the auto-X computer software. It was found that all the samples show orthorhombic structure at room temperature.

\section{CALCULATION OF UNITCELL PARAMETERS AND GRAIN SIZE}

Unitcell parameters of different compositions of SPN system have been obtained from auto-X computer software by using the data obtained from X-RD and average grain size is obtained using PHILIPS PSEM 515, HOLLAND, SEM photographs.

The average grain size determined on selected composition were: $\mathrm{NaNbO}_{3}$ $8.1 \mu, \mathrm{Na}_{.5} \mathrm{~K}_{.5} \mathrm{NbO}_{3}-7 \mu$ and $\mathrm{KNbO}_{3}-2 \mu$, which matches with previously reported results ${ }^{5,7} \mathrm{NaNbO}-8.0 \mu, \mathrm{Na}_{.5} \mathrm{~K}_{.5} \mathrm{NbO}_{3}-5.6 \mu, 6.0 \mu$ and $\mathrm{KNbO}_{3}-2 \mu$.

Comparison of our values for ceramic samples and NBS data ${ }^{10,12}$ for $\mathrm{KNbO}_{3}$ \& $\mathrm{NaNbO}_{3}$ pure samples are as under :-

\section{Our Data}

$$
\begin{aligned}
& -\mathrm{a}\left(\mathrm{A}^{0}\right)=3.950-3.93766 \sqrt{ } 2 \\
& \mathrm{~b}\left(\mathrm{~A}^{0}\right)=3.875-3.88075 \times 4 \\
& \mathrm{c}\left(\mathrm{A}^{0}\right)=3.914 \quad-\quad 3.89241 \sqrt{2}
\end{aligned}
$$$$
\text { Data }{ }^{9,10}
$$

\section{Our Data}
$\mathrm{KNbO}_{3^{-}} \mathrm{a}\left(\mathrm{A}^{0}\right)=4.027-$
$\mathrm{b}\left(\mathrm{A}^{0}\right)=4.057-$

$c\left(A^{0}\right)=3.914 \quad-$
NBS \& others

Data $^{11,12,13}$

$4.02697 \sqrt{ } 2$

$4.04557 \sqrt{ } 2$

3.9739

Table-1. Subcell parameters of $\mathrm{K}_{1-\mathrm{x}} \mathrm{Na}_{\mathrm{x}} \mathrm{NbO}_{3}$ for different $\mathrm{x}$ values

\begin{tabular}{|l|c|c|c|}
\hline \multirow{2}{*}{ Composition } & \multicolumn{2}{|c|}{ Subcell } & Parameters \\
\cline { 2 - 4 } & $\mathbf{a}\left(\mathbf{A}^{\mathbf{0}}\right)$ & $\mathbf{b}\left(\mathbf{A}^{\mathbf{0}}\right)$ & $\left.\mathbf{c} \mathbf{( A}^{\mathbf{0}}\right)$ \\
\hline $\mathrm{Na}_{.8} \mathrm{~K}_{2} \mathrm{NbO}_{3}$ & 3.979 & 3.950 & 3.915 \\
\hline $\mathrm{Na}_{.6} \mathrm{~K}_{.} \mathrm{NbO}_{3}$ & 3.996 & 3.973 & 3.931 \\
\hline $\mathrm{Na}_{.5} \mathrm{~K}_{.5} \mathrm{NbO}_{3}$ & 3.994 & 4.016 & 3.935 \\
\hline $\mathrm{Na}_{.2} \mathrm{~K}_{.8} \mathrm{NbO}_{3}$ & 4.002 & 4.040 & 3.946 \\
\hline
\end{tabular}

Fig. 1 shows SEM patterns for different compositions of PSN system. The variation of subcell parameters with varying composition has been plotted in Fig.2. 


\section{DIELECTRIC MEASUREMENTS}

Dielectric measurements on $\mathrm{K}_{1-\mathrm{x}} \mathrm{Na}_{\mathrm{x}} \mathrm{NbO}_{3}$ samples for different $\mathrm{x}$ values were performed on the model FLUKE PM6306 RCL meter at 0.1, 1, 10, 100 and $1000 \mathrm{kHz}$ at room temperature. The variation of dielectric constant and loss tangent with frequency, for $\mathrm{x}=0, .1, .2, .4, .5$ at $35^{\circ} \mathrm{C}$, is shown in Figs. $3 \& 4$ and is tabulated in Tables $2 \& 3$, respectively.

Table - 2. Variation of dielectric constant with frequency, at $35^{\circ} \mathrm{C}$

\begin{tabular}{|c|c|c|c|c|c|}
\hline \multirow{2}{*}{ Composition } & \multicolumn{5}{|c|}{ Dielectric Constant } \\
\hline & ( 0.1 kHz) & ( $1 \mathrm{kHz})$ & ( $10 \mathrm{kHz})$ & $(100 \mathrm{kHz})$ & ( $1000 \mathrm{kHz})$ \\
\hline $\mathrm{NaNbO3}$ & 19.99 & 20.7 & 20.53 & 20.37 & 21.65 \\
\hline Na.9K.1NbO3 & 47.9 & 46.8 & 45.82 & 45.01 & 45.47 \\
\hline Na.8K.2NbO3 & 123.19 & 116.54 & 114.6 & 112.74 & 113.18 \\
\hline Na.6K.4NbO3 & 294.35 & 284.55 & 277.94 & 270.9 & 264.77 \\
\hline Na.5K.5NbO3 & 235.07 & 218.87 & 207.11 & 207.11 & 205.8 \\
\hline
\end{tabular}

Table -3 . Variation of loss tangent with frequency, at $35^{\circ} \mathrm{C}$

\begin{tabular}{|c|c|c|c|c|c|}
\hline \multirow{2}{*}{ Composition } & \multicolumn{5}{|c|}{ Loss Tangent } \\
\hline & ( 0.1 kHz) & $(1 \mathrm{kHz})$ & ( $10 \mathrm{kHz})$ & ( 100 kHz) & $(1000 \mathrm{kHz})$ \\
\hline $\mathrm{NaNbO3}$ & .047 & .012 & .007 & .007 & .016 \\
\hline Na.9K.1NbO3 & .049 & .015 & .011 & .012 & .015 \\
\hline Na.8K.2NbO3 & .055 & .018 & .012 & .012 & .017 \\
\hline Na.6K.4NbO3 & .117 & .065 & .025 & .020 & .022 \\
\hline Na.5K.5NbO3 & .076 & .040 & .020 & .013 & .019 \\
\hline
\end{tabular}




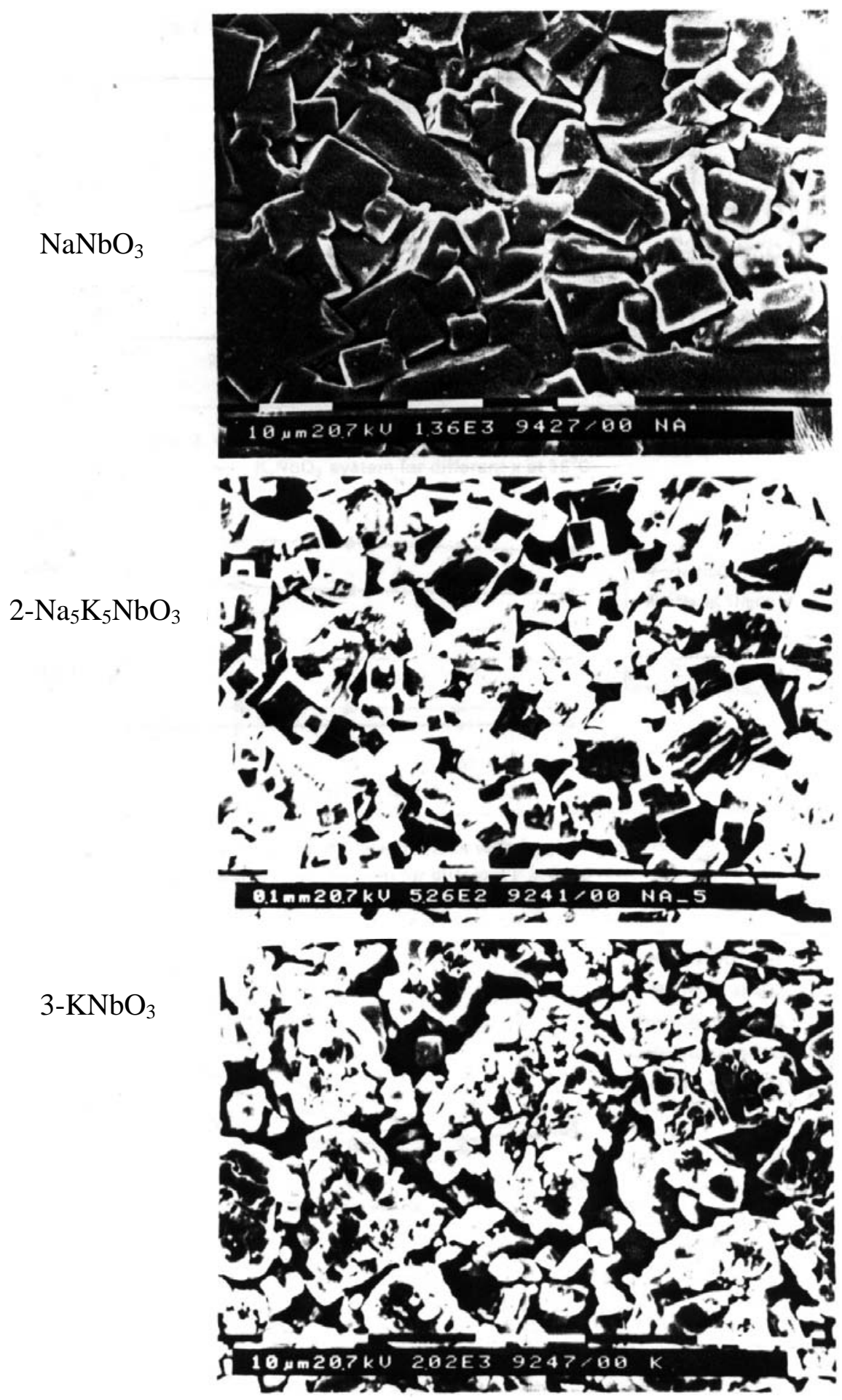

Fig 1. SEM photographs for different compositions of $\mathrm{Na}_{1-\mathrm{x}} \mathrm{K}_{\mathrm{x}} \mathrm{NbO}_{3}$ 
Fig. 2. Effect of Potassium on the subcell parameters of $\mathrm{NaNbO}_{3}$
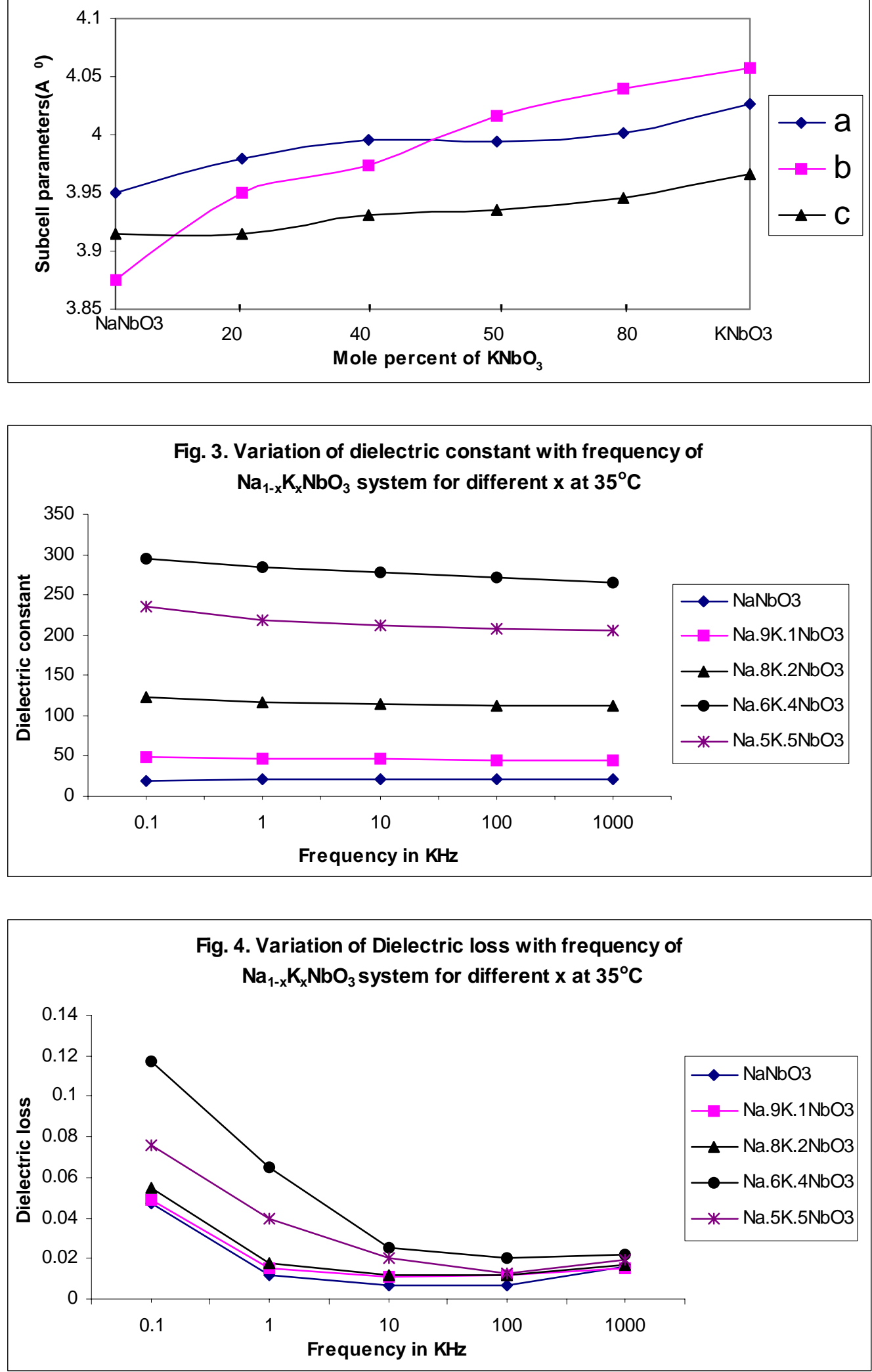


\section{CONCLUSION}

It is observed that the grain size of the $\mathrm{K}_{1-\mathrm{x}} \mathrm{Na}_{\mathrm{x}} \mathrm{NbO}_{3}$ system is decreasing with increasing percentage of potassium. The value of grain size thus calculated for the compositions agree with previous reported results ${ }^{5,7}$.

Fig. (2) shows the variation of unitcell parameters, i.e., a, b, \& c axis with composition of $\mathrm{K}_{1-\mathrm{x}} \mathrm{Na}_{\mathrm{x}} \mathrm{NbO}_{3}$ system. It is observed that the unitcell parameters show an increasing nature with the increase in concentration of potassium atoms in the system. This behavior seems to be good as per expectations because due to larger size of the potassium atoms as compared to sodium atoms. Unitcell parameters of the system increases with the increase in potassium concentration in the mixture.

Fig.3. shows the dependence of dielectric constant on frequency for different $\mathrm{x}$ values in $\mathrm{K}_{1-\mathrm{x}} \mathrm{Na}_{\mathrm{x}} \mathrm{NbO}_{3}$, at $35^{\circ} \mathrm{C}$. It is observed that the dielectric constant decreases with increasing frequency. Up to $50 \%$ of potassium concentration in $\mathrm{K}_{1-\mathrm{x}} \mathrm{Na}_{\mathrm{x}} \mathrm{NbO}_{3}$ dielectric constant increases with the increasing concentration of potassium. At $x=.5$ in $\mathrm{K}_{1-\mathrm{x}} \mathrm{Na}_{\mathrm{x}} \mathrm{NbO}_{3}$ a sudden decrease in the value of dielectric constant is observed for the applied frequencies.

The loss tangent also decreases with the increase of frequency and shows the variation similar to dielectric constant with changing concentration, as shown in Fig. 4.

\section{ACKNOWLEDGEMENTS}

The authors are thankful to DST New Delhi for financial assistance, Materials Science Research Center, IIT Madras \& WADIA institute Dehradun for providing lab. facilities.

\section{REFERENCES}

1. Jr. J. E. May, Ultrasonic Delay Lines, Bell Labs. Record, 35[1] 212(1956).

2. G. Shirane, R. Newnham and R. Pipinsky Phys. Rev. 96, 581(1954).

3. L. Egerton and D. M. Dillon, J. Amer. Cer. Soc. 42 438(1959).

4. V. J. Tennery and K. W. Hang J. Appl. Phys. 39, 4749(1969).

5. S. Narayana Murty, K.V. Rama Murty, K. Umakantham and A. Bhanumathi Ferroelectrics 102, 243(1990).

6. P. Vousden Acta Crystal. 4, 373 (1951).

7. G. H. Heartling, J. Amer. Cer. Soc. 504 429(1967).

8. Natl. Bur. Stand. (U.S.) Monogr. 25, 18,64 (1981).

9. A.C. Sakowski- Cowley, K. Lukaszewicz and H.D.Megaw, Acta Crystallogr. B25, 851 (1969).

10. Natl. Bur. Stand. (U.S.) Monogr. 25, 17,62 (1980).

11. L.Katz, H.D.Megaw, Acta Crystallogr. 22, 639 (1967).

12. E. A. Wood, Acta Cryst. 4, 353 (1951). 